International Journal of Molecular Sciences

ISSN 1422-0067

www.mdpi.com/journal/ijms

Article

\title{
Constitutive Expression of Thermobifida fusca Thermostable Acetylxylan Esterase Gene in Pichia pastoris
}

\author{
Chao-Hsun Yang ${ }^{1, \dagger}$, Kun-I Lin ${ }^{2, \dagger}$, Gen-Hung Chen ${ }^{1}$, Yu-Fen Chen ${ }^{1}$, Cheng-Yu Chen ${ }^{1}$, \\ Wei-Lin Chen ${ }^{1}$ and Yu-Chun Huang ${ }^{1, *}$
}

1 Department of Cosmetic Science, Providence University, 200, Chung-Chi Rd., Taichung, 43301, Taiwan; E-Mails chyang@pu.edu.tw (C.-H.Y.); ghchen2@pu.edu.tw (G.-H.C); yfchen@pu.edu.tw (Y.-F.C.); zychan1268@gmail.com (C.-Y.C); wei.lin46@gmail.com (W.-L.C) Department of Obstetrics \& Gynecology, Chang Bing Show Chwan Memorial Hospital, No. 6 Lugong Rd. Lukang Zhen, Changhua County, Taiwan; E-Mail: konyi@xuite.net

$\dagger$ These authors contributed equally to this work.

* Author to whom correspondence should be addressed; E-Mail: ychuang@pu.edu.tw.

Received: 17 November 2010; in revised form: 1 December 2010 / Accepted: 9 December 2010 / Published: 15 December 2010

\begin{abstract}
A gene encoding the thermostable acetylxylan esterase (AXE) in Thermobifida fusca NTU22 was amplified by PCR, sequenced and cloned into the Pichia pastoris X-33 host strain using the vector $\mathrm{pGAPZ} \alpha \mathrm{A}$, allowing constitutive expression and secretion of the protein. Recombinant expression resulted in high levels of extracellular AXE production, as high as $526 \mathrm{U} / \mathrm{mL}$ in the Hinton flask culture broth. The purified enzyme showed a single band at about $28 \mathrm{kDa}$ by SDS-polyacrylamide gel electrophoresis after being treated with endo- $\beta-N$-acetylglycosaminidase $\mathrm{H}$; this agrees with the predicted size based on the nucleotide sequence. About $70 \%$ of the original activity remained after heat treatment at $60{ }^{\circ} \mathrm{C}$ for three hours. The optimal $\mathrm{pH}$ and temperature of the purified enzyme were 8.0 and $60{ }^{\circ} \mathrm{C}$, respectively. The properties of the purified AXE from the P.pastoris transformant are similar to those of the AXE from an E. coli transformant.
\end{abstract}

Keywords: acetylxylan esterase (AXE); Pichia pastoris; Thermobifida fusca; constitutive expression 


\section{Introduction}

Xylan is a major hemicellulose component of plants and is the most abundant renewable polysaccharide in nature. The complex composition and structure of xylan varies across different plant species [1,2]. It is composed of D-xylopyranosyl residues joined by $\beta$-1,4-glycosidic linkages. Some of these xylosyl residues can be substituted at the $\mathrm{C} 2$ and/or $\mathrm{C} 3$ positions with acetic acid, 4-O-methylglucuronic acid and arabinose [3]. It is not surprising that the synergistic actions of a consortium of microbial enzymes are required for the complete degradation of xylan. Endo- $\beta$-1,4-xylanase (EC 3.2.1.8) can randomly cleave the polysaccharide backbone into shorter xylooligosaccharides. These xylooligosaccharides are further degraded by other glycoside hydrolases and esterases [1,2]. Acetylxylan and xylooligosaccharides are deesterified by acetylxylan esterases (EC 3.1.1.72). These enzymes have been found and isolated from many genera, including Trichoderma [4], Aspergillus [5], Penicillium [6], Schizophyllum [7], Rhodotorula [8], Streptomyces [9], Fibrobacter [10], Bacillus [11], Hypocrea [12], Volvariella [13], Neocallimastix [14] and Thermobifida [15].

The importance and development of industrial biotechnology processing has led to the utilization of microbial enzymes in various applications. To produce enzymes for the development of enzymatic degradation of renewable lignocelluloses, we have isolated a potent extracellular lignocellulolytic enzyme-producing thermophilic actinomycete, Thermobifida fusca NTU22, from compost soils collected in Taiwan [16]. Interestingly, it has been reported that $T$. fusca can produce intracellular and extracellular acetylxylan esterases (AXEs) on oat-spelt xylan [15]. One of the extracellular AXEs was purified and some of its properties were discussed. The molecular mass of the purified enzyme was estimated to be $30 \mathrm{kDa}$ by SDS-PAGE and $28 \mathrm{kDa}$ by gel filtration on Sepharose CL-6B, indicating that the AXE from T. fusca NTU22 is a monomer. The pI value of the purified enzyme was estimated to be 6.55 by isoelectric focusing gel electrophoresis. The N-terminal amino acid sequence of the purified esterase was ANPYERGP. The optimum $\mathrm{pH}$ and temperature for the purified enzyme were 8.0 and $80^{\circ} \mathrm{C}$, respectively. $\mathrm{Zn}^{2+}, \mathrm{Hg}^{2+}, \mathrm{PMSF}$ and DIPF inhibited the enzyme activity. The Km value for $p$-nitrophenyl acetate and acetylxylan were $1.86 \mu \mathrm{M}$ and $0.15 \%$, respectively [17]. The axe gene, which encodes the AXE from T. fusca NTU22, was cloned, sequenced and expressed in Escherichia coli (Accession No. HM 193859). The gene consists of 786 base pairs and encodes a protein of 262 amino acids. The $\mathrm{G}+\mathrm{C}$ content of the axe coding sequence was $66.9 \%$ and the protein had a predicted isoelectric point of 6.34. The deduced amino acid sequence of the AXE exhibited a high degree of similarity with BTA-hydrolase from T. fusca DSM43793, esterase from Thermobifida alba and lipase from Streptomyces albus [18].

In the light of economic benefits, several thermostable enzyme genes from thermophilic microorganisms have been cloned and expressed in mesophilic microorganisms to reduce the energy needed for cultivation $[19,20]$. E. coli is the first choice for heterologous protein expression due to the ease of genetic manipulation, availability of efficient genetic tools, high transformation efficiency and rapid growth rates. However, misfolding and intracellular production often presents the risk of inclusion body formation. In this study, we expressed the AXE gene from T. fusca NTU22 in a host system other than E. coli because of its potential application as a food supplement. Recently, among many mesophilic host systems, Pichia pastoris, methylotrophic yeast capable of performing many 
eukaryotic posttranslational modifications, has been considered as an excellent host system for heterologous proteins expression. It is well known that expression can be driven by the strong alcohol oxidase I (AOX1) promoter under methanol induction [21]. In addition, the glyceraldehyde-3phosphate dehydrogenase (GAP) promoter has been used for constitutive expression of several heterologous proteins without methanol induction in $P$. pastoris [14].

The aim of this study was to constitutively express the AXE gene (axe) from the thermophilic actinomycetes, $T$. fusca NTU22, in P. pastoris X-33. Some properties of the heterologous expressed enzyme were also investigated.

\section{Results and Discussion}

\subsection{Amplification and Construction of the AXE Gene in P. pastoris}

In order to amplify the AXE gene from plasmid ER405-6, two primers were designed for PCR. According to agarose gel electrophoresis of the PCR product, one major band was apparent at approximately $800 \mathrm{bp}$ and could be eluted for further processes. The axe coding sequence was cloned into the pGAPZaA vector using the $\mathrm{XhoI} / \mathrm{XbaI}$ restriction sites as described earlier. This construction allowed axe coding sequence to be theoretically in-frame with the $\alpha$-factor secretion signal in pGAPZ $\alpha$ A. Following a sequence check, the construct, denoted as pGAPZ-axe, was BglII-linearized and electroporated into $P$. pastoris X-33. Four transformants were selected for high resistance to Zeocin $(2,000 \mu \mathrm{g} / \mathrm{mL})$. The genomic PCR assay revealed that all the transformants contained an integrated axe coding sequence in the genomic DNA. Among these four transformants, the transformant (pGAPZ-axe) could produce the highest AXE activity and was selected for further experiments.

\subsection{Expression of the AXE Gene (axe) in P. pastoris}

The fermentation conditions for constitutive expression of the AXE were investigated in a $500 \mathrm{~mL}$ Hinton flask loaded with $50 \mathrm{~mL}$ YPD broth at $28^{\circ} \mathrm{C}$. Transformant (pGAPZ-axe) grew logarithmically from 24 to 48 hours and then entered a stationary phase (Figure 1). The biomass reached approximately 22 of the $\mathrm{OD}_{600}$ value after 48-hours incubation. The enzyme production pattern in this transformant indicated that AXE synthesis began in the middle logarithmic phase and continued to be produced during the stationary phase where the maximum activity $(526 \mathrm{U} / \mathrm{mL})$ was reached in the culture broth. The AXE activity was about 500-times higher than that observed when expressed from an E. coli transformant [18]. The control strain, P. pastoris (pGAPZ $\alpha \mathrm{A}$ ), could also produce esterase activity under the same culture conditions (data not shown). In the GAP promoter expression system, the cloned heterologous protein will be expressed along with cell growth if the protein is not toxic for the cell $[23,24]$. Such a result was observed in this study. As shown in Figure 1, the rapid production of the extracellular AXE occurred in parallel with an increase in biomass accumulation of the $P$. pastoris transformant. 
Figure 1. Time course for the expression of AXE activity by $P$. pastoris transformant (pGAPZ-axe). Cells were grown aerobically in a $500 \mathrm{~mL}$ Hinton flask loaded with $50 \mathrm{~mL}$ of medium consisting of YPD broth, and were incubated at $28^{\circ} \mathrm{C}, 150 \mathrm{rpm}$ for 96 hours. $(\bullet)$, esterase activity; ( $\square), \mathrm{OD}_{600}$.

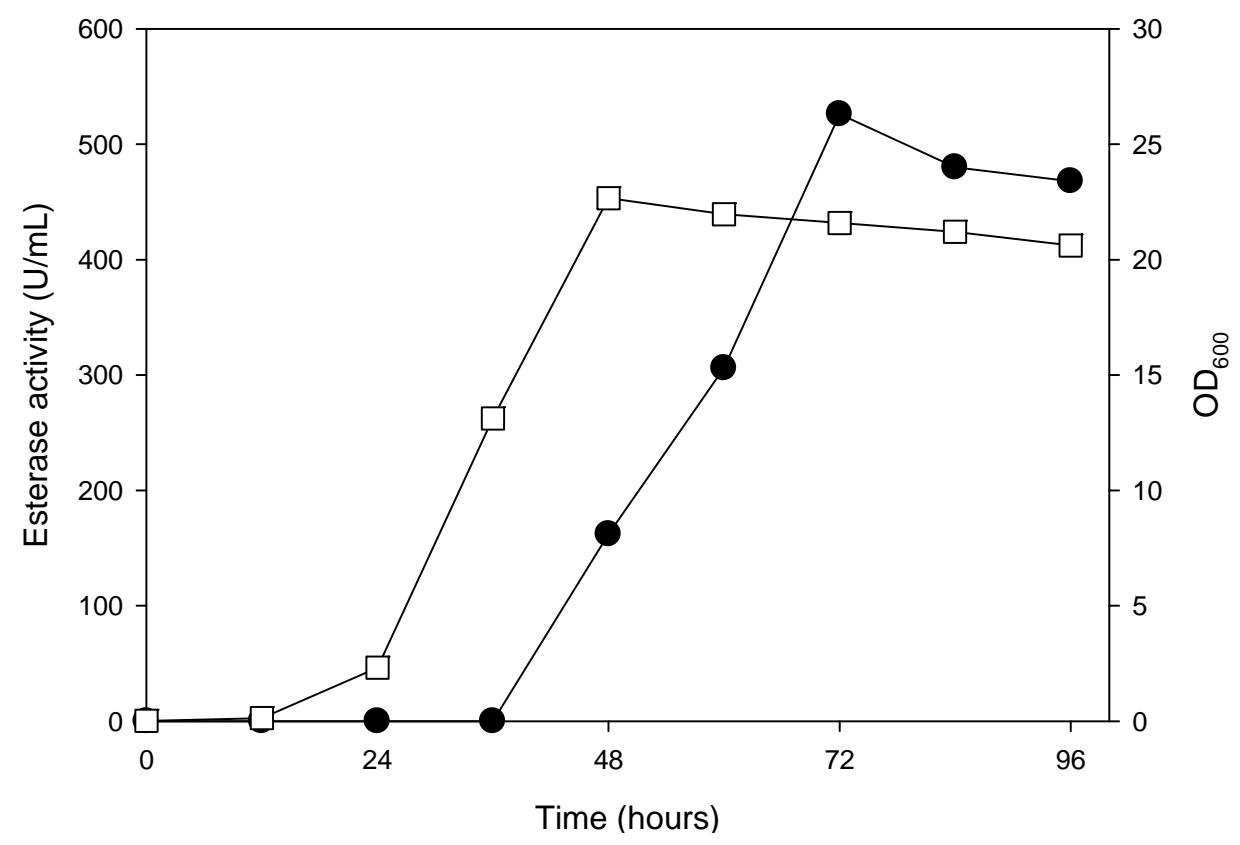

\subsection{Purification of AXE from P. pastoris Transformant}

The purification of AXE was performed as described in the Experimental Section. The results of the total purification are summarized in Table 1 . The purified enzyme exhibited $0.68 \%$ of the total initial activity and there was a 26.1-fold increase in specific activity when compared with the crude culture filtrate. The amount of extracellular proteins in the culture broth of the $P$. pastoris transformant was fewer than that in the cell free extract of the E. coli transformant. This will facilitate the application of the enzyme in an industrial process immediately without complicated purification procedures. Most of the non-specific esterase activity from the P. pastoris host was lost in the ultrafiltration process, resulting in a decrease of the purification fold.

Table 1. Summary of the purification of AXE from $P$. pastoris transformant (axe).

\begin{tabular}{cccccc}
\hline $\mathbf{0}$ & $\begin{array}{c}\text { Total activity } \\
\text { (U) }\end{array}$ & $\begin{array}{c}\text { Total protein } \\
\text { (mg) }\end{array}$ & $\begin{array}{c}\text { Specific } \\
\text { activity } \\
\text { (U/mg) }\end{array}$ & $\begin{array}{c}\text { Purification } \\
\text { (fold) }\end{array}$ & $\begin{array}{c}\text { Yield } \\
\text { (\%) }\end{array}$ \\
\hline Culture & $469,698.8$ & 637.1 & 737.2 & 1.0 & 100.0 \\
Ultrafiltration & $32,729.1$ & 283.5 & 115.4 & 0.2 & 6.97 \\
Ni-Sepharose $^{\mathrm{TM}}$ & $3,214.0$ & 0.167 & $19,245.5$ & 26.1 & 0.68 \\
\hline
\end{tabular}

\subsection{Properties of AXE from P. pastoris Transformant}

As shown in Figure 2, after being treated with endo- $\beta-N$-acetylglycosaminidase $H$ for deglycosylation, the purified enzyme showed an apparent single protein band on SDS-PAGE ( $10 \%$ gel). The subunit size of the single protein band was estimated to be $28 \mathrm{kDa}$ from its mobility 
relative to standard proteins by SDS-PAGE. The optimal $\mathrm{pH}$ and temperature of the AXE from P. pastoris transformant (pGAPZ-axe) were 8.0 and $60{ }^{\circ} \mathrm{C}$, respectively. About $70 \%$ of the original AXE activity remained after heat treatment at $60{ }^{\circ} \mathrm{C}$ for three hours. Yang et al. [17] reported that $70 \%$ of the AXE activity from $T$. fusca NTU22 remained after heat treatment at $70{ }^{\circ} \mathrm{C}$ for three hours. Apparently the thermostability of the AXE from the P. pastoris transformant is lower than the enzyme from the original strain, T. fusca NTU22.

Figure 2. SDS-PAGE of purified protein sample containing AXE from P. pastoris transformant (axe). Lane $\mathrm{M}=$ molecular weight markers; 1 = protein sample containing AXE from $P$. pastoris transformant.

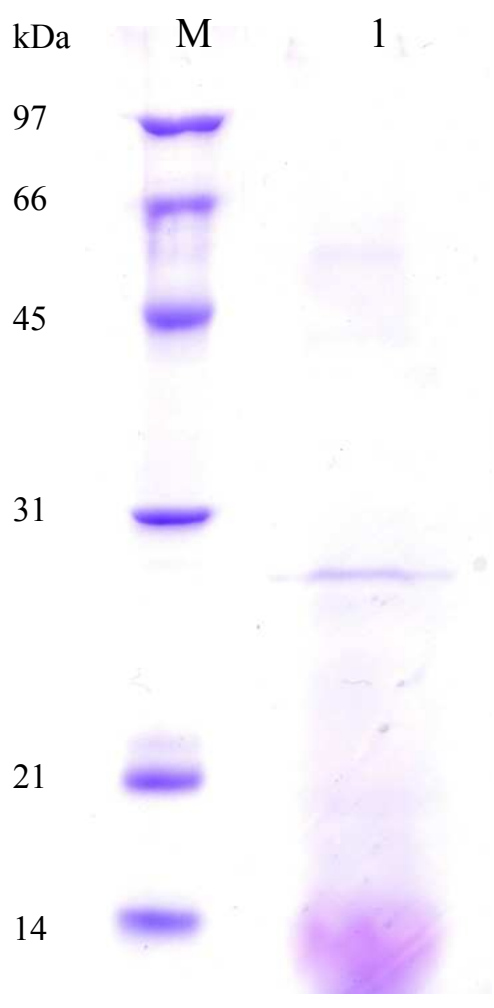

\section{Experimental Section}

\subsection{Microorganisms and Vectors}

Thermophilic actinomycetes, T. fusca NTU22, which was isolated from compost soils collected in Taiwan, was used in this study [16]. P. pastoris X-33 and pGAPZ $\alpha$ A were purchased from Invitrogen (Sandiego, CA, USA). The plasmid propagation in the expression work was accomplished with E. coli Top 10 (Invitrogen, Sandiego, CA, USA). The plasmid ER405-6 was constructed with the pGEM ${ }^{\circledR}$-T Easy Vector and a 800 bp inserted fragment, which possessed an AXE gene axe [18].

\subsection{Materials}

Yeast extract, peptone, tryptone and agar were purchased from BD (Sparks, MD, USA). Zeocin was obtained from Cayla (Toulouse, France). Restriction endonucleases and T4 DNA ligation kit were purchased from Roche (Mannheim, Germany). For polymerase chain reactions, the Vio Twin Pack 
Kits comprising VioTag DNA polymerase, polymerase chain reaction buffer and deoxynucleotides were obtained from Viogene (Sunnyvale, CA, USA). Ni-Sepharose ${ }^{\mathrm{TM}}$ High Performance resin was purchased from GE Healthcare (Little Chalfont, UK). PiNK Prestained Protein Ladder was purchased from GeneDirex (Las Vegas, NV, USA). The protein assay kit was obtained from Bio-Rad Laboratories (Hercules, CA, USA). Endo- $\beta$ - $N$-acetylcosaminidase $H$ was purchased from New England Biolabs Inc. (Beverly, MA, USA). Inorganic salts and all other chemicals were purchased from Sigma (St. Louis, MO, USA).

\subsection{Construction of the Amylase Expression Plasmid}

The T. fusca NTU22 AXE gene was amplified using the primers 5'-AATTCTAGACCAAATGGACAGGTGCTGCGATACTCTTC-3' (Xhol site is underlined) and 5'-AACTCGAGAAACGTGAGGCTGAAGCAGCGGCGAATCCGTATGAACGG-3' (XbaI site is underlined), using ER405-6 as the template. The amplification was performed using a DNA thermal cycler (Perkin Elmer, MA, USA) with the following conditions: the first step was initiated at $95{ }^{\circ} \mathrm{C}$ for $5 \mathrm{~min}$, followed by 30 cycles of $95{ }^{\circ} \mathrm{C}$ for $30 \mathrm{~s}, 65^{\circ} \mathrm{C}$ for $30 \mathrm{~s}$ and $72{ }^{\circ} \mathrm{C}$ for $90 \mathrm{~s}$, and the final extension was carried out at $72{ }^{\circ} \mathrm{C}$ for 7 min. The gel-purified PCR product was digested with $X$ hoI and $\mathrm{XbaI}$ and cloned into $\mathrm{XhoI}$ and $\mathrm{XbaI}$ digested pGAPZ $\alpha$ A. After being transformed into E. coli Top 10 , one recombinant plasmid designated as pGAPZ $\alpha$-axe was selected on low salt LB agar plates ( $5 \mathrm{~g} / \mathrm{L}$ yeast extract, $10 \mathrm{~g} / \mathrm{L}$ tryptone, $5 \mathrm{~g} / \mathrm{L} \mathrm{NaCl}, 15 \mathrm{~g} / \mathrm{L}$ agar, and adjusted $\mathrm{pH}$ to 7.5 ) containing $25 \mu \mathrm{g} / \mathrm{mL}$ Zeocin. The proper insert orientation was checked by restriction analysis and sequencing as described above [25].

\subsection{Transformation and Screening of $\mathrm{P}$. pastoris}

Ten micrograms of recombinant plasmid (pGAPZ $\alpha-a x e$ ) was linearized with BglII, and electroporated into $P$. pastoris X-33 using the following conditions: $1.5 \mathrm{kV}, 25 \mu \mathrm{F}, 200 \mathrm{ohm}$ and $5 \mathrm{~ms}$, using a GenePulser (Bio-Rad, CA, USA). The transformants were selected at $28^{\circ} \mathrm{C}$ on YPDS agar plates (10 g/L yeast extract, $20 \mathrm{~g} / \mathrm{L}$ peptone, $20 \mathrm{~g} / \mathrm{L}$ dextrose, $20 \mathrm{~g} / \mathrm{L}$ agar and $1 \mathrm{M}$ sorbitol) containing $100 \mu \mathrm{g} / \mathrm{mL}$ Zeocin for 4-6 days. Screening for high level expression transformants was done by replicating the colonies obtained from the YPDS agar plates containing $100 \mu \mathrm{g} / \mathrm{mL}$ Zeocin onto YPDS agar plates with a higher Zeocin concentration $(2,000 \mu \mathrm{g} / \mathrm{mL})$. Transformants with higher Zeocin-resistance were obtained and checked for the integration of the construct into the $P$. pastoris $\mathrm{X}-33$ genome by genomic PCR [26].

\subsection{Biomass and Esterase Activity Assay}

Biomass production of the $P$. pastoris transformant was evaluated by measuring the optical density at $600 \mathrm{~nm}\left(\mathrm{OD}_{600}\right.$ value). Esterase activity was assayed as described by Kodemi et al. [27] with slight modification. We used spectrophotometric analysis with p-nitrophenyl acetate as a substrate; the release of $p$-nitrophenol was determined at $405 \mathrm{~nm}$. One unit of enzyme activity was defined as the amount of the enzyme releasing $1 \mu \mathrm{mol}$ of $p$-nitrophenol per min at $25^{\circ} \mathrm{C}, \mathrm{pH}$ 8.0. 


\subsection{Cultivation and Expression of AXE in Hinton Flask}

The transformant resistant to high concentration of Zeocin was incubated in $50 \mathrm{~mL}$ YPD broth (10 g/L yeast extract, $20 \mathrm{~g} / \mathrm{L}$ peptone, $20 \mathrm{~g} / \mathrm{L}$ dextrose) in $500 \mathrm{~mL}$ Hinton flasks and shaken (150 rpm) at $28{ }^{\circ} \mathrm{C}$. After the cultivation was carried out for several days, the culture broth was centrifuged at $10,000 \times g$ for $30 \mathrm{~min}$ at $4{ }^{\circ} \mathrm{C}$ and finally the supernatant was tested for AXE activity.

\subsection{Enzyme Purification}

All purification procedures were done at $4{ }^{\circ} \mathrm{C}$ in $20 \mathrm{mM}$ Tris- $\mathrm{HCl}$ buffer $(\mathrm{pH} 7.5)$ unless otherwise stated. After 72-hours of cultivation of the P. pastoris transformant (pGAPZ $\alpha$-axe) in a $500 \mathrm{~mL}$ Hinton flask, the fermentation broth was centrifuged at 3,000 $\times \mathrm{g}$ for $30 \mathrm{~min}$ to remove cells. The supernatant was then applied to a Ni-Sepharose ${ }^{\mathrm{TM}}$ High Performance column $(1.13 \mathrm{~cm} \times 8 \mathrm{~cm})$ pre-equilibrated with Tris-HCl buffer. After washing with wash buffer $(20 \mathrm{mM}$ Tris- $\mathrm{HCl}, 500 \mathrm{mM}$ sodium chloride, $40 \mathrm{mM}$ imidazole; $\mathrm{pH}$ 7.5) to remove the unbound protein, the enzyme was eluted with elution buffer (20 mM Tris- $\mathrm{HCl}, 500 \mathrm{mM}$ sodium chloride, $500 \mathrm{mM}$ imidazole; $\mathrm{pH}$ 7.5). The eluted enzymatically active fractions were pooled and used as the purified enzyme.

\subsection{SDS-Polyacrylamide Gel Electrophoresis (SDS-PAGE)}

The molecular mass of the purified enzyme was determined by using SDS-PAGE (10\% polyacrylamide). PiNK Prestained Protein Ladder was used as molecular mass standards. The electrophoresis was carried out at $150 \mathrm{~V}$ for $1 \mathrm{~h}$. The gel was stained with $0.27 \%$ Coomassie Brilliant Blue R-250, and destained by washing overnight with a mixture of acetic acid-methanol-water $(10: 20: 70, \mathrm{~V} / \mathrm{V})$.

\subsection{Deglycosylation of AXE from P. pastoris Transformant}

The purified enzyme from $P$. pastoris transformant was deglycosylated by denaturing the glycoprotein at $100^{\circ} \mathrm{C}$ for $10 \mathrm{~min}$, and then endo- $\beta$ - $N$-acetylglycos-aminidase $\mathrm{H}$ was added to perform deglycosylation at $37^{\circ} \mathrm{C}$ for $1 \mathrm{~h}$. All manipulations followed the manufacturer's instructions.

\section{Conclusions}

We are interested in the production of lignocellulolytic enzyme from local thermophilic actinomycetes to explore their use in novel biotechnological applications. The thermostable AXE gene (axe) from thermophilic actinomycetes, T. fusca NTU22, was heterologously expressed in the mesophilic host system, P. pastoris, for further exploration. This GAP expression system is more suitable than the $A O X$ expression system for large-scale production because the hazard and cost associated with the storage and delivery of large volumes of methanol are eliminated. Thus, the features of the GAP expression system may contribute significantly to the development of cost-effective methods for large-scale production of heterologous recombinant proteins. These findings hold promise in large-scale production of thermostable AXE and application in both agricultural and food industries. 


\section{Acknowledgements}

Financial support for this study from the National Science Council of the Republic of China (NSC98-2320-B-126-001-MY3) is gratefully acknowledged.

\section{References}

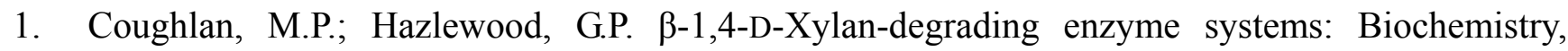
molecular biology and applications. Appl. Biochem. Biotechnol. 1993, 17, 259-289.

2. Christov, L.P.; Prior, B.A. Esterases of xylan-degrading microorganisms: Production, properties, and significance. Enzyme Microb. Technol. 1993, 15, 460-475.

3. Kato, Y; Nevins, D.J. Isolation and identification of $O$-(5-O-feruloyl- $\alpha$-L-arabinofuranosyl)$1(\rightarrow 3)-O-\beta$-D-xylopyranosyl-( $1 \rightarrow 4)-D-x y l o p y r a n o s e$ as a component of Zea shoot cell-walls. Carbohydr. Res. 1985, 137, 139-150.

4. Biely, P.; Cote, G.L. Kremnicky, L.; Greene, R.V.; Tenkanen, M. Action of acetylxylan esterase from Trichoderma reesei on acetylated methyl glycosides. FEBS Lett. 1997, 420, 121-124.

5. Khan, A.W.; Lamb, K.A.; Overend, R.P. Comparison of natural hemicellulose and chemically acetylated xylan as substrates for the determination of acetyl-xylan esterase activity in Aspergilli. Enzyme Microb. Technol. 1990, 12, 127-131.

6. Chavez, R.; Bull, P.; Eyzaguirre, J. The xylanolytic enzyme system from the genus Penicillium. J. Biotechnol. 2006, 123, 413-433.

7. Biely, P.; MacKenzie, C.R.; Schneider, H. Production of acetyl xylan esterase by Trichoderma reesei and Schizophllum commune. Can. J. Microbiol. 1988, 34, 767-772.

8. Lee, H.; To, R.J.; Latta, R.K.; Biely, P.; Schneider, H. Some properties of extracellular acetylxylan esterase produced by the yeast Rhodotorula mucilaginosa. Appl. Environ. Microbiol. 1987, 53, 2831-2834.

9. Dupont, C.; Daigneault, N.; Shareck, F.; Morosoli, R.; Kluepfel, D. Purification and characterization of an acetyl xylan esterase produced by Streptomyces lividans. Biochem. J. 1996, 319, 881-886.

10. McDermid, K.P.; MacKenzie, C.R.; Forsberg, C.W. Esterase Activities of Fibrobacter succinogenes subsp. succinogenes S85. Appl. Environ. Microbiol. 1990, 56, 127-132.

11. Krastanova, I.; Guarnaccia, C.; Zahariev, S.; Degrassi, G.; Lamba, D. Heterologous expression, purification, crystallization, X-ray analysis and phasing of the acetyl xylan esterase from Bacillus pumilus. Biochim. Biophys. Acta 2005, 1748, 222-230.

12. Li, X.L.; Skory, C.D.; Cotta, M.A., Puchart, V.; Biely, P. Novel family of carbohydrate esterases, based on identification of the Hypocrea jecorina acetyl esterase gene. Appl. Environ. Microbiol. 2008, 74, 7482-7489.

13. Liu, X.; Ding, S. Molecular characterization of a new acetyl xylan esterase (AXEII) from edible straw mushroom Volvariella volvacea with both de- $O$-acetylation and de- $N$-acetylation activity. FEMS Microbiol. Lett. 2009, 295, 50-56. 
14. Pai, C.K.; Wu, Z.Y.; Chen, M.J.; Zeng, Y.F.; Chen, J.W.; Duan, C.H.; Li, M.L.; Liu, J.R. Molecular cloning and characterization of a bifunctional xylanolytic enzyme from Neocallimastix patriciarum. Appl. Microbiol. Biotechnol. 2010, 85, 1451-1462.

15. Bachmann, S.L.; McCarthy, A.J. Purification and cooperative activity of enzymes constituting the xylan-degrading system of Thermomonospora fusca. Appl. Environ. Microbiol. 1991, 57, 2121-2130.

16. Liu, W.H.; Yang, C.H. The isolation and identification of a lignocellulolytic and thermophilic actinomycete. Food Sci. Agric. Chem. 2002, 4, 89-94.

17. Yang, C.H.; Liu, W.H. Purification and properties of an acetylxylan esterase from Thermobifida fusca. Enzyme Microb. Technol. 2008, 42, 181-186.

18. Huang, Y.C.; Chen, G.H.; Chen, Y.F.; Chen, W.L.; Yang, C.H. Heterologous expression of thermostable acetylxylan esterase gene from Thermobifida fusca and its synergistic action with xylanase for the production of xylooligosaccharides. Biochem. Biophys. Res. Commun. 2010, doi:10.1016/j.bbrc.2010.08.136.

19. Zamost, B.L.; Nielsen, H.K.; Starnes, R.L. Thermostable enzymes for industrial application. J. Ind. Microbiol Biotechnol. 1991, 8, 71-82.

20. Cheng, Y.F.; Yang, C.H.; Liu, W.H. Cloning and expression of Thermobifida xylanase gene in the methylotrophic yeast Pichia pastoris. Enzyme Microb. Technol. 2005, 37, 541-546.

21. Cereghino, J.L.; Cregg, J.M. Heterologous protein expression in the methylotrophic yeast Pichia pastoris. FEMS Microbiol. Rev. 2000, 24, 45-66.

22. Zhang, A.L.; Zhang, T.Y.; Luo, J.X.; Chen, S.C.; Guan, W.J.; Fu, C.Y.; Peng, S.Q.; Li, H.L. Constitutive expression of human angiostatin in Pichia pastoris by high-density cell culture. J. Ind. Microbiol. Biotechnol. 2007, 34, 117-122.

23. Cos, O.; Ramón, R.; Montesinos, J.L.; Valero, F. Operational strategies, monitoring and control of heterologous protein production in the methylotrophic yeast Pichia pastoris under different promoters: A review. Microb. Cell Fact. 2006, 5, 17. doi:10.1186/1475-2859-5-17.

24. Goodrick, J.C.; Xu, M.; Finnegan, R.; Schilling, B.M.; Schiavi, S.; Hoppe, H.; Wan, N.C. High-level expression and stabilization of recombinant human chitinase produced in a continuous constitutive Pichia pastoris expression system. Biotechnol. Bioeng. 2001, 74, 492-497.

25. Yang, C.H.; Huang, Y.C.; Chen, C.Y.; Wen, C.Y. Expression of Thermobifida fusca thermostable raw starch digesting alpha-amylase in Pichia pastoris and its application in raw sago starch hydrolysis. J. Ind. Microbiol. Biotechnol. 2010, 37, 401-406.

26. Reddy, S.T.; Kumar, S.N.; Haas, A.L.; Dahms, N.M. Biochemical and functional properties of the full-length cation-dependent mannose 6-phosphate receptor expressed in Pichia pastoris. Biochem. Biophys. Res. Commun. 2003, 309, 643-651.

27. Kademi, A.; Ait-Abdelkader, N.; Fakhreddine, L.; Baratti, J.C. A thermostable esterase activity from newly isolated moderate thermophilic bacterial strains. Enzyme Microb. Technol. 1999, 24, $332-338$.

(C) 2010 by the authors; licensee MDPI, Basel, Switzerland. This article is an open access article distributed under the terms and conditions of the Creative Commons Attribution license (http://creativecommons.org/licenses/by/3.0/). 